\section{To modernize and open up. . .}

FrançOIs Kourilsky, the molecular biologist from Marseilles who is now directorgeneral of CNRS, was appointed to his post by Hubert Curien in 1988 with firm instructions to "modernize and open up" CNRS. How well does he believe the task is going?

$\mathrm{He}$ is anxious that the organization should not be mistaken for the whole of French science, noting that it accounts for less than 19 per cent of the total civil budget. But he is pleased about the growing links with industry. At the latest count, industrial contracts with CNRS laboratories number 2,700 , nearly two for each of the 1,300 distinct research units. Their total value is FF1,300 million, more than a tenth of the total budget. There is, he believes, a long way to go before the laboratories will be at a loss to know where next to sell their services.

Industrial contracts seem to serve a wider purpose than to keep the wolf from the door of some CNRS laboratories. To this outsider, one of the wider consequences has been to persuade industrial companies that there is, indeed, some benefit to be won from research and development.

Kourilsky says that, until recently, French industry has not significantly increased the numbers of people it employed on research and development. But now, he says, there is a surge in the recruitment of people, especially in fields such as mathematics, computer science, electronics and chemistry, not to mention molecular biology. Evidently he shares Curien's view that those who work for him should be doubly honoured if they leave to work in industry.

But is there a danger that the balance between contract work and basic research will be too much skewed against the latter? Not as things are, he holds. Perhaps the difficulties will arise when, as the volume of contract work continues to grow, but patchily, some laboratories will find themselves short of people for their core programmes while other, lacking contracts, will have people but only modest research funds.

Kourilsky agrees with Curien (see page 126) that the salaries of young researchers should be improved, but considers that the promotion bottlenecks are "still a problem".

On the scheme to provide university teachers with research funds through a committee within the education ministry, he holds that the source of funds should be independent of the university system. "On that, I diverge from Claude Allègre." The problem is that of evaluation. He regrets that the Napoleonic universities "lack independence".

CNRS differs from most comparable organizations in the large number $(1,300)$ of laboratories in which its people are dispersed. The range is from a handful of people to some scores. So how are new laboratories started, and old laboratories disbanded?

As always, it is easier to start than to stop. The process of evaluation, Kourilsky believes, is accurate and reliable. But the law requires that a decision either to open or close a laboratory should be taken only on the basis of expert advice. The process

\section{BUDGET PRESSURE}

THE albatross around the neck of CNRS is the risk of being blamed for everything that goes wrong.

Although, on balance, CNRS attracts more praise than protest, the years ahead may be more difficult. The budget squeeze on CNRS's disposable expenditure is one source of strain. The need for some means of financing university research will be a further complication.

CNRS is potentially the more vulnerable because it has a finger in every pie. The existence of INSERM notwithstanding, for example, the life science division (one of seven) takes a quarter of the total budget. But CNRS is also strong in the humanities and social sciences. (The Science de l'Homme et de la Societé division takes more than 10 per cent - see figure below.)

Over the decades since the early 1960s, when it was common to find CNRS researchers working in isolation, and on a shoestring, in cubby-hole laboratories throughout the University of Paris, the organization has shown itself to be remarkably resilient and adaptable.

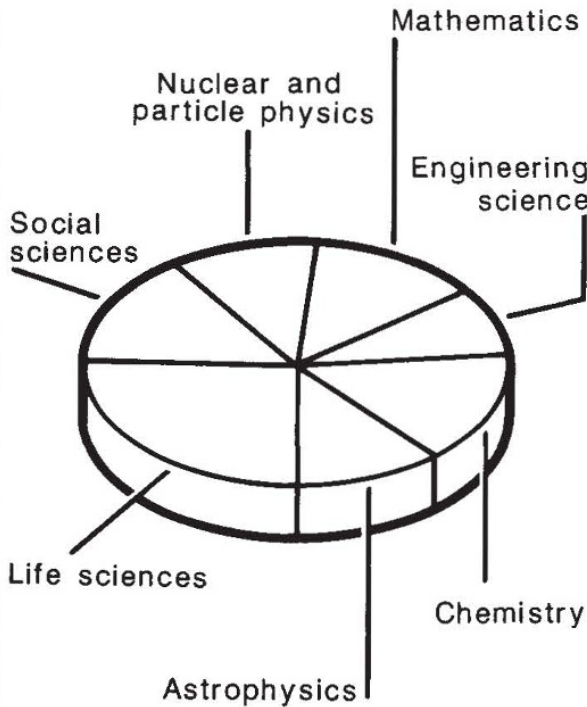

Distribution of CNRS funds between divisions, 1990. can be slow.

On the future of the organization, he believes that links with universities will be strengthened, together with those with industry. But there are particular opportunities, he believes, in the emerging pattern of a single Europe for forming stronger links with overseas laboratories.

Kourilsky has not been at his job for long enough for his impact on CNRS to have become clear. Moving the bureaucracy will not be a simple task. But he seems to have one important augury on his side - a largely enthusiastic research force.

\title{
Staying ahead of the game
}

The Chevènement upheaval of the early 1980s may nevertheless be one of the best things to have happened to CNRS, confirming its central place in the French scheme of things as well as the role to which it had already aspired of being one of the chief means of research planning in France.

The then-new director-general of CNRS, Pierre Papon, made forward planning his centrepiece. After an elaborate consultation within CNRS and industry, a score (literally 20) research themes were singled out for special attention, and became the basis for research planning in succeeding years. While the interest of the particular themes may since have been attenuated, the mechanism remains. CNRS is forever organizing consultations among interested groups to determine what weight should be given to particular themes.

During the same period, the influence of CNRS on university research has been formalized and legitimized, by the device of associated (associés) laboratories, set up by means of formal contracts between universities and CNRS, and in which CNRS and university employees work side by side. (Other research organizations, such as INSERM and CEA, follow the same practice.) Between them, the research agencies have come to provide support - people as well as money - for most of the outstanding research at French universities. Throughout France, CNRS is this year supporting 1,003 research groups by this mechanism. (It also has 366 in-house research units, some of them very small.)

There is no shortage of academic research groups looking for support of this kind. By a curious device invented in 1982, the education ministry nominates (on the advice of CNRS) research groups considered deserving of outside support - recommandé is the designation which may look for such crumbs as fall from the tables of CNRS and the other grandes organismes of research, perhaps 
in the end for full support. On one reckoning, there are a further 1,000 of these research groups waiting in the wings.

Now, as always, the snag is the budget. Despite the general growth of funds for research, the CNRS share of the civil budget has not grown as quickly as the whole. And the commitment of nearly 75 per cent of CNRS's share to the salaries of its employees means that its disposable income is shrinking. On one estimate, annual research expenses at CNRS account for FF110,000 a researcher, compared with FF180,000 at INRA and FF215,000 at INSERM (the best heeled of the research-support organizations).

CNRS seems bent on righting that imbalance. University research groups, especially the recommandes, were chilled at the end of last year when Kourilsky (see previous page) remarked that "CNRS does not have the means to support all university research groups" even when they are excellent. That sharpens the dispute over the education ministry's plan to provide research funds direct, but it also requires that CNRS itself should choose between being the daring cat that steals the cream from the top of the milk and being the pillar of the establishment it has become used to being.

That is for the years ahead. Meanwhile,

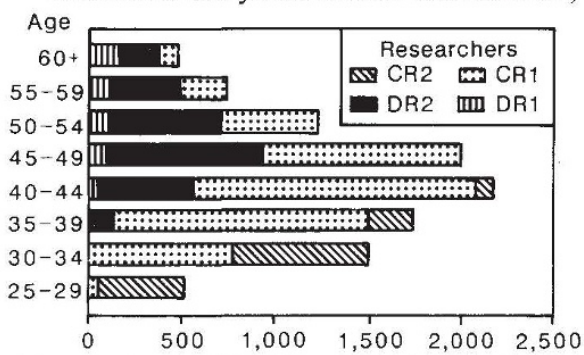

Age-structure of CNRS research population, 1988.

CNRS has kept its options open. The organization is typified by its post-SecondWorld-War headquarters at Gif-surYvette, in the suburbs southwest of Paris. The 'campus' is a park, acquired cheaply in a deal that requires CNRS to keep a team of gardeners on its books so as beautify the park. On one side is a fairly recent chateau (now a visitors' hostel) and, on the other, a collection of laboratories embodying the recent history of CNRS in bricks and concrete (mostly concrete from a less prosperous age). Despite the gardeners, the campus seems seedy.

What CNRS has been doing is plain enough: it has been following trends apparent elsewhere. Although nuclear and particle physics are still responsible for FF790 million, the proportion has fallen from 22 per cent in 1978 to 10.9 per cent in 1989. But life sciences, less than 18 per cent in 1978 , are now 25.3 per cent (and employ more than 2,800 researchers at CNRS in-house and out-house units). Inevitably, the life sciences division of CNRS spends more of its budget on recur- rent costs than on equipment and (less predictably) just about half of its total budget on associated and joint (with other councils) laboratories. In the first half of the 1980 s, engineering sciences (especially computers) grew quickly - and the number of research posts virtually doubled but now chemistry is the most quickly growing.

CNRS has also been ageing. In 1988, only 35 per cent of its researchers were younger than 40 . Although the recruitment and promotion rates are now to be increased, it is difficult to see them quickly creating the bottom-heavy pyramidal agestructure one would expect to find in a research organization. No wonder that Curien (see page 126) says that he is glad that industry threatens to hire away senior people.

\section{A club-like atmosphere}

THOSE who work for CNRS behave like members of a club because they are members of a club. To be a CNRS researcher is to be a member of a distinctive group, as if it were to be the French Navy or the corps diplomatique. But CNRS is, of course, not quite as grand.

The sense of club is easily explained: for at least the past decade, entrants to CNRS have won their places in the public service by competition in the common concours. They vividly appreciate the distinction between themselves (who are in) and those who are out. At least until recently, they could be reasonably sure that they would work permanently in this branch of the public service, with occasional postings elsewhere.

But this commonality does not engender a dull sense of uniformity. Different research laboratories have their own distinctive spirit. Some are plainly riding high, perhaps sustained by industrial contracts or grants for special projects. Others harbour a deep sense of neglect. They are inevitably the laboratories most oppressed by the bureaucracy of their parent, which is organized into seven divisions and no fewer than 36 sections, each with its own secretariat.

The underlying difficulty is the small proportion of the CNRS budget free for research expenses. More than 75 per cent of the budget is committed in advance to salaries; heat, light and maintenance take a substantial proportion of the rest. (INSERM seems better placed in this regard.)

Travel funds are not too hard to come by; most people acknowledge they can make one substantial overseas journey every year or two, while European Communities sources are increasingly used for travel within Europe. But the proportion of a laboratory's total budget remaining in a director's hands for research expenses may be relatively very small, perhaps less than 10 per cent of his salary bill.

Yet CNRS abounds with people who hold the highest opinions of their organization. For many, the sense of security and freedom they enjoy makes up for the gap between government and industrial salaries. One, the director of a laboratory at Gif-sur-Yvette, says that CNRS provides unique opportunities for research. Another gives it as his opinion that CNRS, whatever its faults, has become the dominant arbiter of quality in French science. The organization's willingness to enter into collaborations with universities and industrial companies, sometimes taking the initiative in forming them, is generally commended.

One British member of a joint CNRS/ INSERM laboratory says that he is more settled, and more productive, in France than he had been at a British university. He reckons that the continuing shortage of academic positions in Britain must soon stimulate a soutwards stampede across the English Channel when British people realize that, at the outset, all the French they need is that required to keep body and soul together.

Another Briton at another laboratory, fresh from a postdoctoral position in the United States and with an enviable reputation for the development of a new technique, says that he chose the CNRS laboratory from among half a dozen at which he had been offered a position. (Sybaritic considerations seem to have played a part in the decision.) Testimonials of this kind abound. Because, to paraphrase Anna Karenina, contented employees are all alike, but discontented employees differ in their discontent. The following complaints against the organization are necessarily more voluminous. Their balance should not be judged by the space they occupy.

First, there are problems about people. Laboratories not well-endowed with outside funds are less able than others to keep competent young people at work while they compete for permanent places at successive concours for permanent positions. The result, some say, is that able people are often lost to the system at the beginning of their careers.

Filling vacancies is a constant headache. If a vacancy should arise, even among the technical or administrative staff, it cannot automatically be filled. Instead, the section or even division to which the laboratory belongs will at least consider whether the vacancy should instead be awarded to some other unit. According to 